\title{
Comparison of Greenhouse Gas Emissions Per Capita Per Year Among Countries Considering Methane Emissions
}

\author{
Zhang Yü ${ }^{1}$, Su Mingshan ${ }^{2, *}$, Yang Shanshan ${ }^{1}$ \\ ${ }^{1}$ Statistical and Accounting Research Department, National Center for Climate Change Strategy and International Cooperation (NCSC), \\ Beijing, China \\ ${ }^{2}$ National Center for Climate Change Strategy and International Cooperation (NCSC), Beijing, China
}

Email address:

zhangyu@ncsc.org.cn (Zhang Yu), sums ancsc.org.cn (Su Mingshan)

${ }^{*}$ Corresponding author

To cite this article:

Zhang Yu, Su Mingshan, Yang Shanshan. Comparison of Greenhouse Gas Emissions Per Capita Per Year Among Countries Considering Methane Emissions. Earth Sciences. Vol. 9, No. 5, 2020, pp. 219-226. doi: 10.11648/j.earth.20200905.18

Received: August 21, 2020; Accepted: September 15, 2020; Published: October 27, 2020

\begin{abstract}
The cumulative emissions of $\mathrm{CO}_{2}$ and $\mathrm{CH}_{4}$ had a great impact on the global climate, and the responsibility of countries around the world to achieve greenhouse gas (GHG) emission control goals should be based on the concept of fairness and sustainable development. In this paper, from the perspective of interpersonal equity, based on the annual GHG emissions per capita, using the $\mathrm{CO}_{2}$ and $\mathrm{CH}_{4}$ emissions data of 23 major countries from 1961 to 2017, the ratio for GHG emission per capita per year and the ratio for carbon dioxide emission per capita per year in various countries were calculated with 1961 and 1990 as the starting years, the countries were also sequenced and sorted to analyze the extent to which major countries occupy limited global emissions space at different time scales and GHG ranges. The results showed that the ratio of GHG emission per capita per year in developed countries such as the United States and Canada were far higher than the world average, China was significantly lower than the average, India was much lower than the average. In addition, lengthening the time scale and incorporating the methane emissions from the planting and breeding industry (agriculture activities) had a significant impact on the the ratio of GHGemission per capita and national classification. It can be more conducive to judge the world's average annual GHG emissions, reflect the global emission space occupied by each countries comprehensively and objectively, and scientifically support policymakers in formulating action plan for GHGemission reduction and control, which was of practical significance.
\end{abstract}

Keywords: GHG Emissions Space Use Ratio, Emission Per Capita Per Year, Carbon Emissions,

Methane Emissions from Agriculture

\section{Introduction}

Climate change is a global challenge that matters for the living environment of humans and the development as well as prosperity of all countries. Effective adaptation and mitigation of climate change requires international cooperation, as well as long-term joint action for emission reduction and control on a global scale based on the concept of fairness and sustainable development. The increase of total GHG emissions, including $\mathrm{CO}_{2}$, has resulted in global warming, glacier melting, reduction of sea ice area, and acceleration of sea level, which poses a catastrophic risk to small island countries. $\mathrm{CH}_{4}$, the second largest GHG only after $\mathrm{CO}_{2}$, accounts for $16 \%$ of the global GHG emissions [1]. The global warming potentials (GWP) of $\mathrm{CH}_{4}$ within 20-year and 100-year after emissions were about 84 times and 28 times that of $\mathrm{CO}_{2}$ respectively [2], which has contributed to $25 \%$ of the global warming [3]. In China's national GHG emission inventories, $\mathrm{CH}_{4}$ is listed among the major $\mathrm{GHG}$ emissions, mainly from agriculture, coal mining, oil and gas production. According to the Third National Communication of the People's Republic of China on Climate Change and China's National Greenhouse Gas Emissions Inventory 2010, $\mathrm{CO}_{2}$ and $\mathrm{CH}_{4}$ represented $80.4 \%$ and $12.2 \%$ of China's total GHG emissions (with land use, land-use changes, and forestry, i.e. LULUCF) in 2010 respectively. $\mathrm{CH}_{4}$ emissions from agriculture reached 22,414 million tons, of which 
enteric fermentation accounted for $26.2 \%$, rice planting $22.1 \%$, and manure management $16.6 \%$. In light of this, it is of great significance to study the accounting of GHG emissions in various countries, especially the space of GHG emissions. At present, most studies on annual per capita GHG emissions only cover $\mathrm{CO}_{2}$ emissions from energy and industrial activities, and fail to include the high $\mathrm{CH}_{4}$ emissions with strong greenhouse effect.

In order to reflect the space of GHG emissions of various countries and the share in global limited emission allowance more comprehensively and objectively, this paper examined GHG emissions per capita per year in major countries between 1961 and 2017, including $\mathrm{CH}_{4}$ emissions from breeding industry and $\mathrm{CO}_{2}$ emissions from energy activities and industrial processes. Based on the study of Su Mingshan [4] while taking into account interpersonal equity, this study calculated the ratio of $\mathrm{GHG}$ emissions and only for $\mathrm{CO}_{2}$ emissions in major countries of the world, and extended the calculation year of termination from 2013 to 2017 , to analyze the extent to which major countries occupy the world's limited emission of global space. Changes in the ratio for GHG emissions and the ranking of various countries with 1990 and 1961 as the starting years were also discussed. The study will facilitate equitable allocation of global emission allowance and provide more scientific support for decision makers to formulate action plans for GHG emission reduction and control.

\section{Literature Review}

The calculation of cumulative $\mathrm{CO}_{2}$ emissions per capita was based on the premise of insisting on "common but differentiated responsibilities", requiring developed countries to take the lead in fulfilling emission reduction commitments and assume a higher proportion of long-term emission reduction responsibilities. By allocating global limited space of emissions in a fair and reasonable manner, the principle ensures that each country can make the same proportion of contribution to addressing global climate change.

In Poznan climate talks held in December 2008, the Chinese delegation [5] clearly proposed, for the first time, the concept of "cumulative per capita emissions"in the climate negotiations to look at the issue of reduction of global GHG emissions. Miao Xuming [6] proposed the concept of cumulative $\mathrm{CO}_{2}$ emissions per capita, and believed that it reflected emissions both historically and currently. Pan Jiahua et al. [7] investigated the correlation between carbon emissions per capita and economic development in major countries, and analyzed per capita emissions and cumulative per capita carbon emissions. He Jiankun et al. [8] systematically discussed the issue of "equity" in global climate change from different perspectives, and proposed the allocation principle of carbon emission rights featuring convergence of per capita carbon emissions towards the target year and cumulative per capita carbon emissions during the transitional period in countries based on the criteria of equitable carbon emission per capita rights. From the perspective of interpersonal equity and historical responsibility for carbon emissions, Liu Qiang et al. [9] measured the carbon emission allowance of various countries based on the principle of equitable carbon emissions per capita per year, which takes full account of historical demographic changes. Wang Huihui et al. [10] probed into intergenerational and intra-generational equity in carbon emissions using the data of population, gross domestic product (GDP) and carbon emissions of 132 countries around the world from the perspective of historical cumulative emissions. With "cumulative per capita emissions" as the criteria, Ding Zhongli et al. [11] calculated the carbon emission allowance and spatial allocation of countries (1900 - 2050), and divided countries or regions with population of more than 300,000 into four categories.

Su Mingshan [4] defined the ratio of GHG emissions space usage, and from the perspective of interpersonal equity, presented the country ranking by the ratio of GHG emissions space usage and analyzed the country share in global emission allowance, based on comparison of GHG emissions per capita per year of 142 counties with the global level. The results showed that the United States and other Annex I countries unduly occupy the world's limited resources, while the GHG emissions per capita per year of India, Indonesia and other non-Annex I countries were far below than those of the Annex I countries, which was more in line with national historical and current situation, also reflected fairness and therefore has guiding significance. However, the GHG studied only considered $\mathrm{CO}_{2}$ and fluorinated gas (F-gas), and the $\mathrm{CH}_{4}$ gas produced by the agricultural process, which took up a high proportion, has not been calculated. In addition, from the analysis of the results, F-gas has little effect on country classification and ranking results of the ratio for GHG emissions space usage.

\section{GHG Emissions per Capita Per Year and Space Use Ratio}

\subsection{Research Method}

The calculation formulas for the volume of GHG emissions per capita per year and the ratio of GHG emissions space usage of a participant within the studied time frame were shown as Equation 1 [9] and 2 [4] respectively:

$$
\begin{gathered}
\text { GHG emission per capita per year }=\frac{\sum_{\text {starting year }}^{\text {Ending year }} \text { Carbon Emission }}{\sum_{\text {starting year }}^{\text {Ending year }} \text { Population }} \\
\text { pi }=\frac{\text { ei }}{\mathrm{e}}
\end{gathered}
$$

Wherein, $p i$ is the ratio for GHG emissions of party $i$ in the studied time frame; $e i$ indicates the volume of GHG emissions per capita per year of party $i$ in the studied time frame; $e$ indicates the volume of GHG emissions per capita per year of all parties in the studied time frame. In this study, party $i$ 
represents a country.

\subsection{Research Objects and Data Sources}

Considering the significant impact of GHGs such as $\mathrm{CO}_{2}$ and $\mathrm{CH}_{4}$ on global climate change and the availability and completeness of relevant data, this paper examined GHG emissions from energy activities, industrial processes, and agriculture activities of 23 major countries in the period from 1961 to 2017 . These countries included the G20 members, 10 largest carbon emission countries which ranked according to the 2017 International Energy Agency (IEA) data of annual $\mathrm{CO}_{2}$ emissions, and world's top 10 largest agricultural countries. The calculation scope of GHG emissions includes energy activities, industrial production processes, and agricultural activities. GHG emissions from energy activities calculated $\mathrm{CO}_{2}$ emissions from fossil fuel combustion; industrial production processes calculated $\mathrm{CO}_{2}$ emissions from by cement clinker production; agriculture activities calculated $\mathrm{CH}_{4}$ emissions from animal enteric fermentation, manure management and rice planting.

The $\mathrm{CO}_{2}$ emission data was sourced from National GHG Emission Inventories, IEA, Carbon Budget Project, and Carbon Emission Information Analysis Center (CDIAC) [12-15]; The $\mathrm{CH}_{4}$ emission data from the Food and Agriculture Organization (FAO) of the United Nations [16].

The demographic data came from the United Nations Department of Economic and Social Affairs [17].

\section{Calculation Results and Analysis}

Firstly, this paper calculated the average GHG emissions per capita per year of major countries between 1961 to 2017, and then calculated the space use ratio of GHG emissions and only $\mathrm{CO}_{2}$ emissions. Based on the calculation results, the changes in the ratio of GHG emissions space usage and ranking of various countries were compared between calculations with 1990 and 1961 as the starting years respectively.

\subsection{Research Objects and Data Sources}

Using the aforementioned formula, the ratio for $\mathrm{GHG}$ emissions space usage during 1961-2017 was calculated for the 23 countries. Then, a country ranking by the value of ratio is produced, as shown in Figure 1. It can be seen that industrialized developed countries such as the United States, Canada, and Australia have a larger ratio for GHG emissions space usage than emerging economies such as India, Brazil, and China. In particular, the ratio for GHG emissions space usage of the top two countries, i.e. the United States and Australia, exceeded 4, and equals to 15.25 and 14.78 times that of the lowest ranking India respectively, indicating that the ratio for GHG emissions space usage of developed countries such as the United States and Australia were greater than the world average and far higher than that of developing countries, which occupied excessively limited global emission space.

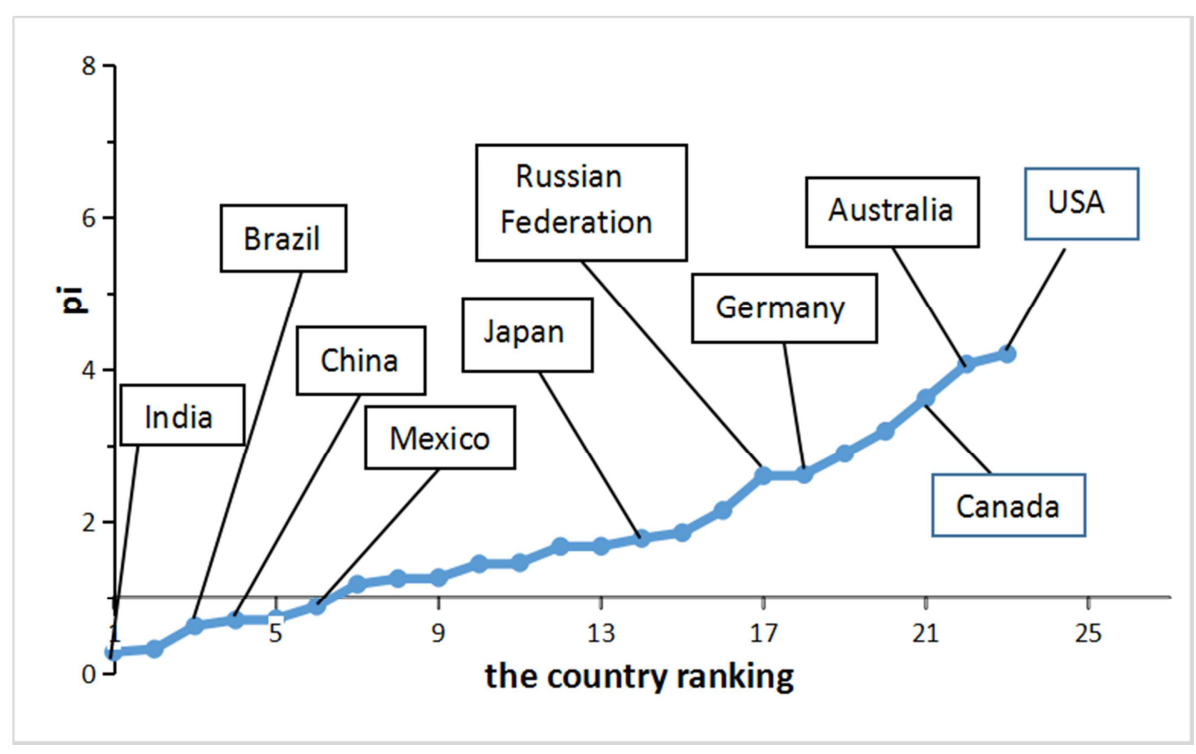

Figure 1. Ratio for GHG emission space usage of major countries in 1961-2017.

Adopting the classification method for the ratio for $\mathrm{GHG}$ emissions space usage proposed by Su Mingshan [6], the 23 countries were classified into nine categories according to the value of ratio: LLLL, LLL, LL, L, E, H, HH, HHH and HHHH, as shown in Table 1, and the world average annual GHG emissions per capita per year was taken as E.

LLLL: $p i<0.30$. GHG emissions per capita per year were far below than E. One country fell into this category.

LLL: $0.30 \leq p i<0.50$. GHG emissions per capita per year was considerably below than E. One country fell into this category.

LL: $0.50 \leq p i<0.70$. GHG emissions per capita per year was moderately below than $\mathrm{E}$. Two countries fell into this category.

L: $0.70 \leq p i<0.90$. GHG emissions per capita per year was slightly below than E. Two countries fell into this category.

E: $0.90 \leq p i<1.11$. GHG emissions per capita per year was equivalent to $\mathrm{E}$. No country fell into this category.

$\mathrm{H}: 1.11 \leq p i<1.43$. GHG emissions per capita per year was 
slightly higher than E. Three countries fell into this category

HH: $1.43 \leq p i<2.00$. GHG emissions per capita per year was significantly higher than E. Six countries fell into this category.

HHH: $2.00 \leq p i<3.33$. GHG emissions per capita per year was absolutely higher than E. Five countries fell into this category.

HHHH: $p i \geq 3.33$. GHG emissions per capita per year was much higher than $\mathrm{E}$. Three countries fell into this category.

Table 1. National Classification about GHG Emission Space Usage Ratio in 1961-2017.

\begin{tabular}{ll}
\hline category & country \\
\hline LLLL & India \\
LLL & Indonesia \\
LL & Brazil, China \\
L & Turkey, Mexico \\
E & \\
H & Iran, Argentina, Spain \\
HH & Republic of Korea, Italy, Israel, France, Japan, South Africa \\
HHH & United Kingdom, Russian Federation, Germany, New Zealand, Saudi Arabia \\
HHHH & Canada, Australia, USA \\
\hline
\end{tabular}

If only the $\mathrm{CO}_{2}$ emissions were considered to calculate the ratio for $\mathrm{CO}_{2}$ emissions of various countries during 1961-2017, the country ranking and classification results were as shown in Figure 2 and Table 2, respectively.

Table 2. National Classification about carbon dioxide Emission Space Usage Ratio in 1961-2017.

\begin{tabular}{ll}
\hline category & country \\
\hline LLLL & India, Indonesia \\
LLL & Brazil \\
LL & \\
L & Turkey, China, Mexico, Argentina \\
E & \\
H & Iran, Spain \\
HH & Italy, Republic of Korea, New Zealand, France, Israel, Japan, South Africa \\
HHH & United Kingdom, Germany, Russian Federation \\
HHHH & Saudi Arabia, Australia, Canada, USA \\
\hline
\end{tabular}

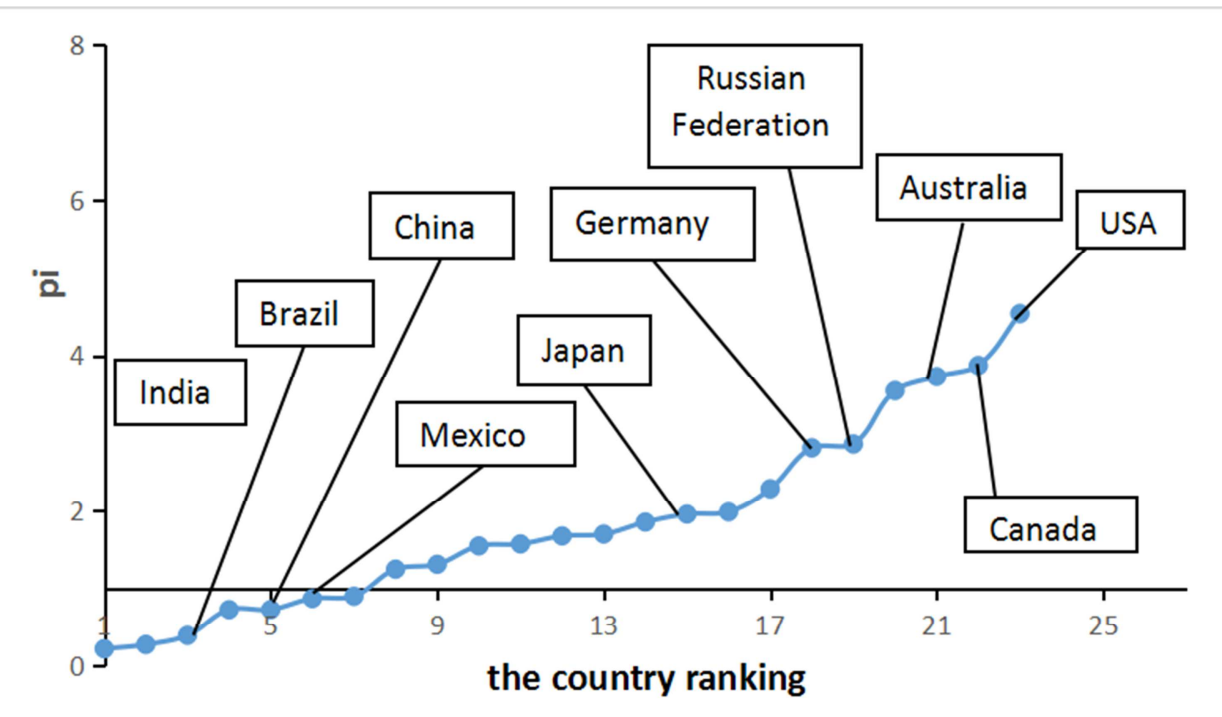

Figure 2. Ratio for carbon dioxide emission space usage of major countries in 1961-2017.

Compared with Figure 1 and Table 1, the ranking changed for 14 countries, involving every category, but the lowest- ranked and highest-ranked countries and their categories remain the same, i.e. India (LLLL) and the United States (HHHH). The number of LLLL category increased from 1 to 2 country as Indonesia moved from LLL category. While number of LLL category does not change with Brazil's joint (formerly in LL category). China and Argentina fell into L category (from LL category and $\mathrm{H}$ category, respectively), which made the number of LL 
category reduced from 2 to 0 , L category increased from 2 to 4 , and $\mathrm{H}$ category decreased from 3 to 2 . In addition to the changes in the country classification already explained above, the number of $\mathrm{HH}$ category reduced from 6 to 7 countries as New Zealand joined from HHH category. With the addition of Saudi Arabia (formerly in HHH category) and the withdrawal of New Zealand, the number of $\mathrm{HHH}$ countries declined from 5 to 3, while the number of $\mathrm{HHHH}$ countries changed from 3 to 4 . Hence, the inclusion of $\mathrm{CH}_{4}$ emissions from agriculture activities (enteric fermentation, manure management, rice cultivation) has a greater impact on the calculation results of the ratio for GHG emissions space usage and classification in various countries, and can more comprehensively reflect the country share in global emission allowance.

\subsection{Ratio for GHG Emissions Space Usage During 1990-2017}

Taking 1990 as a starting point to calculate the ratio for GHG emissions of 23 countries during 1990 - 2017, the country ranking and classification results were as shown in Figure 3 and Table 3, respectively. It can be seen that GHG emissions per capita per year of emerging economies such as India, Indonesia, and Brazil were considerably lower than the world average level. China as the largest developing country, has an emission level close to Mexico, which was equivalent to the the world average, so both fell into E category. Saudi Arabia, Canada, the United States, and Australia belonged to the HHHH category as GHG emissions per capita per year far exceeded the world average and the level of developing countries.

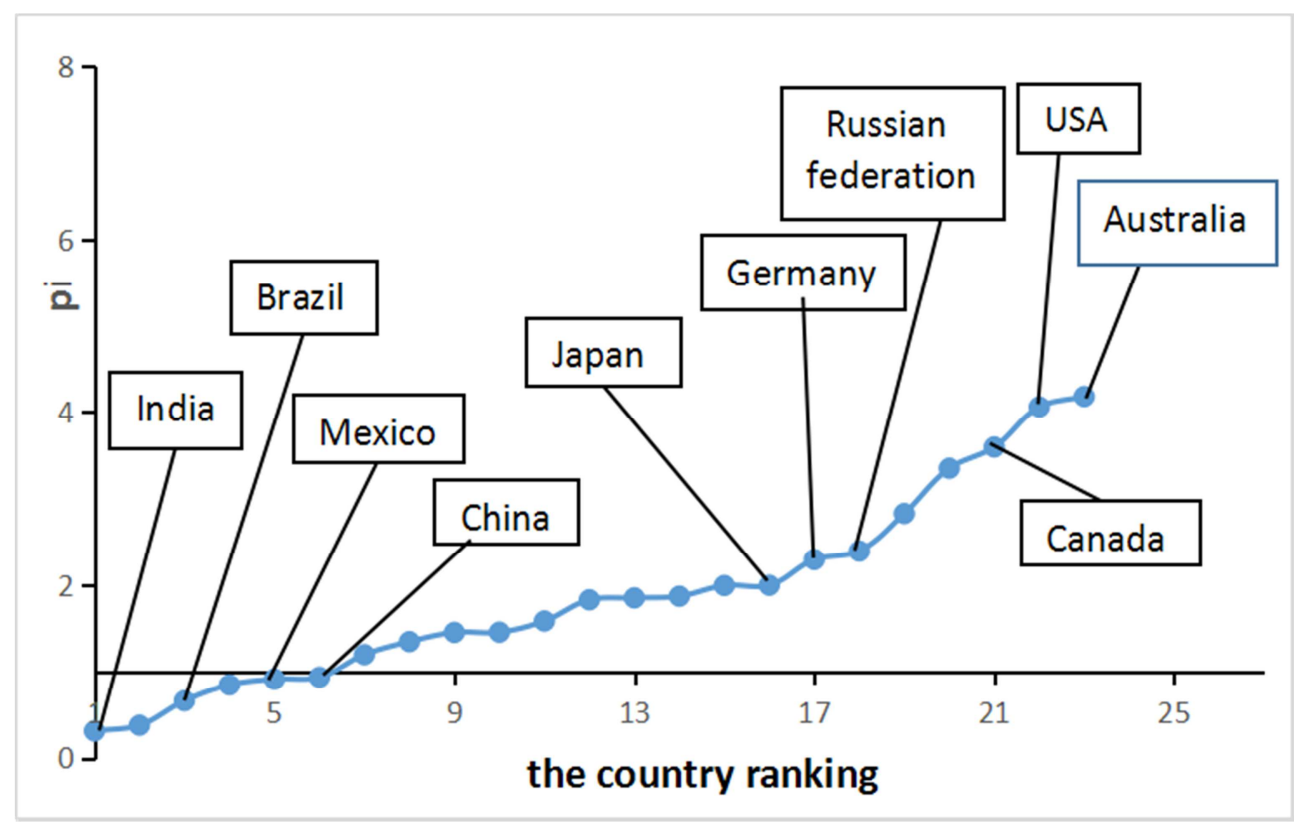

Figure 3. Ratio for GHG emission space usage of major countries in 1990-2017.

Table 1 and Table 3 clearly indicated the differences between cumulative emissions measured with 1990 and 1961 as the starting point. Overall, 17 countries's ranking have varied, the country on the top rank has changed from the
United States to Australia, while the bottom ranked country remained India. In addition, countries included in each category were also varied, specific alterations were as follows.

Table 3. National classification about GHG Emission space usage ratio in 1990-2017.

\begin{tabular}{l|l}
\hline category & country \\
\hline LLLL & \\
LLL & India, Indonesia \\
LL & Brazil \\
L & Turkey \\
E & Mexico, China \\
H & Argentina, Iran \\
HH & France, Spain, Italy, South Africa, Israel, United Kingdom, Republic of Korea, Japan \\
HHH & Germany, Russian Federation, New Zealand \\
HHHH & Saudi Arabia, Canada, USA, Australia \\
\hline
\end{tabular}

India moved to LLL category from LLLL category, which reduced the number of LLLL countries to 0 and increased the number of LLL category from 1 to 2 . With the addition of China (formerly in LL category) and Mexico (formerly in L 
category), the number of $\mathrm{E}$ category rose from 0 to 2 , while both LL category and L category decreased from 2 to 1 . Spain moved from $\mathrm{H}$ category to $\mathrm{HH}$ category, declined the number of $\mathrm{H}$ category countries from 3 to 2 . $\mathrm{HH}$ category grew in number from 6 countries to 8 countries, in addition to the above-mentioned changes in country rankings, the United Kingdom moved from $\mathrm{HHH}$ category to $\mathrm{HH}$ category. As a result of Saudi Arabia moved from $\mathrm{HHH}$ to $\mathrm{HHHH}$ and the United Kingdom's alteration, the number of HHH countries reduced from 5 to 3 , while the number of HHHH countries increased from 3 to 4 . It was not difficult to see that when calculating GHG emissions per capita per year of various countries, the expansion of time scale has a significant effect on the country ranking results of the ratio for GHG emissions and classification. By taking full account of historical emissions, the results can more scientifically and objectively reflect the degree of global emission space occupied by each country.

Table 4. National classification about carbon dioxide emission space usage ratio in 1990-2017.

\begin{tabular}{ll}
\hline category & country \\
\hline LLLL & India \\
LLL & Indonesia, Brazil \\
LL & \\
L & Turkey \\
E & Mexico, Argentina, China \\
H & \\
HH & Iran, France, Spain, Italy, New Zealand, South Africa, United Kingdom \\
HHH & Israel, Republic of Korea, Japan, Germany, Russian Federation \\
HHHH & Saudi Arabia, Canada, Australia, USA \\
\hline
\end{tabular}

If only $\mathrm{CO}_{2}$ emission was considered, the ratio for $\mathrm{CO}_{2}$ emissions space usage of various countries during $1990-$ 2017 can be calculated, the country ranking and classification results were as shown in Figure 4 and Table 4, respectively. Compared with Figure 2 and Table 2, the ranking of 13 countries has changed, involving every category except LL, but the names and categories of lowest-ranked and highest-ranked countries remain the same. As Indonesia moved from LLLL to LLL category, the number of LLL countries increased from 1 to 2 , while the number of LLLL countries decreased from 2 to 1 . There was no change in the LL category. With the move of Argentina, Mexico, and China from L category to the originally empty E category, the number of $\mathrm{L}$ countries decreased from 4 to 1 , while $\mathrm{E}$ category increased to 3 .

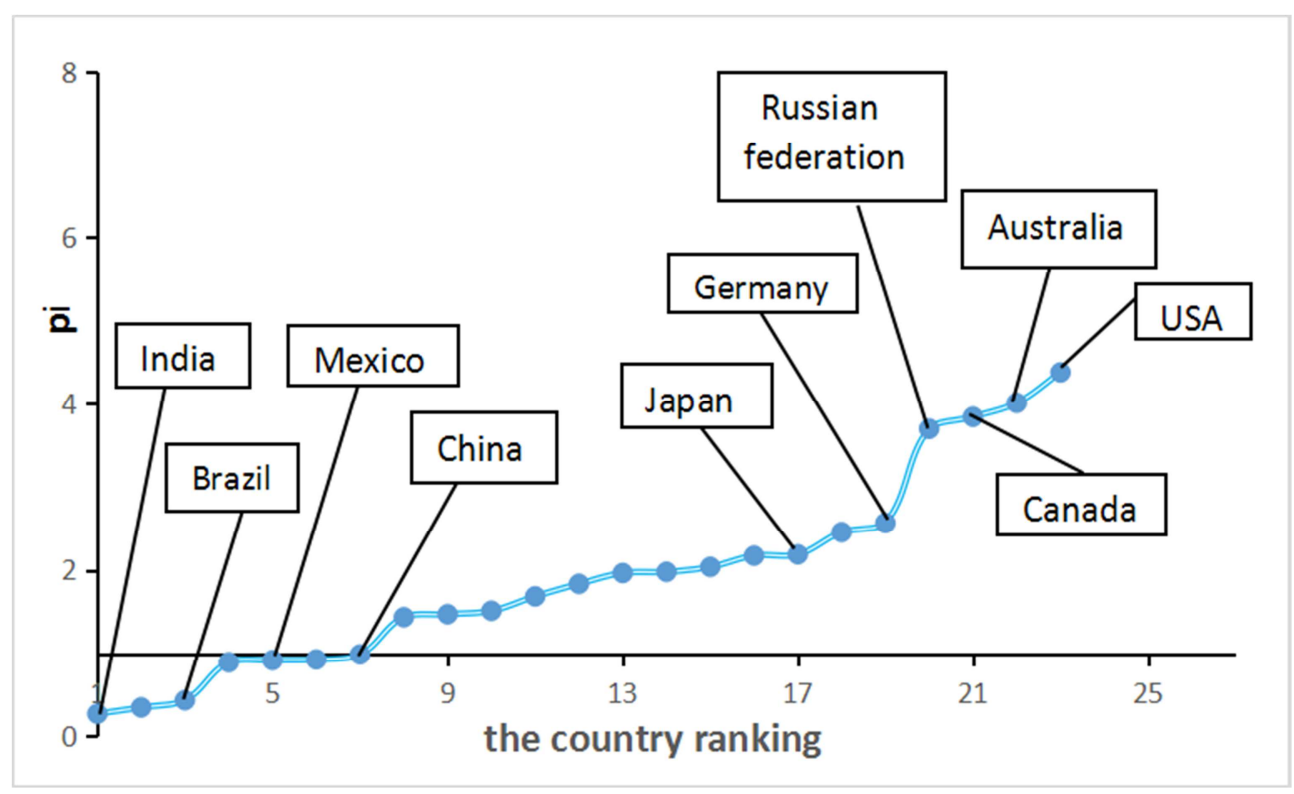

Figure 4. Ratio for carbon dioxide emission space usage of major countries in 1990-2017.

Iran and Spain fell into HH category, instead of H category, but because of the join of the United Kingdom (formerly in HHH category) and the withdrawal of Korea, Japan, Israel (formerly in $\mathrm{HHH}$ category) to $\mathrm{HHH}$ category, the number of $\mathrm{HH}$ countries remained the same and $\mathrm{HHH}$ countries grew from 3 to 5 considering the rise of Israel into $\mathrm{HH}$ category. The same four countries fell into HHHH category, with variance in the ratio and ranking by per capita $\mathrm{CO}_{2}$ emissions The results further proved that a longer time scale that took full account of historical GHG emissions of each country had a significant impact on the ranking results of the GHG emissions space usage ratio per capita per year and country's classification, which can be more conducive to the measurement of GHG emissions per capita per year of 
various countries and the equitable distribution of global emission allowance.

\section{Conclusions}

In summary, the following conclusions can be drawn:

(1) Between 1961 and 2017, the ratio for GHG emissions space usage exceeds 3.33 in the United States, Australia, and Canada, indicating that annual GHG emissions per capita per year of these countries were more than 3.33 times the world average, which excessively took up the limited global emission space. The ratio for GHG emissions ranges from 2.00 to 3.33 in the United Kingdom, Russia, Germany, New Zealand, and Saudi Arabia, absolutely higher than the world average. Within a range of 1.43 to 2.00 , the ratio for GHG emissions in South Korea, Italy, Israel, France, Japan, and South Africa, were moderately higher than the world average. The ratio for GHG emissions of Iran, Argentina, and Spain ranges from 1.11 to 1.43 , slightly higher than world average. In contrast, Turkey and Mexico (0.70-0.90) had a level slightly below the world average, China and Brazil (0.50-0.70) were moderately lower than the world average, Indonesian $(0.30-0.50)$ was considerately below the world average, and India (less than 0.30) was far below the world average.

(2) Incorporating $\mathrm{CH}_{4}$ emissions from agriculture activities (enteric fermentation, manure management, and rice cultivation) into the calculation scope of GHG emissions per capita per year and space use ratio of each country had a significant impact on the results that only consider $\mathrm{CO}_{2}$ emissions. The country ranking and classification results had changed significantly, which can more fully reflect the share to which various cotuntries occupy global emission allowance.

(3) When calculating GHG emissions per capita per year of each country, a longer time scale of the calculation significantly affected country ranking results of GHG emissions space use ratio and the national classification results. By fully taking into account both current and historical emissions of various countries, the approach was more conducive to judge GHG emissions per capita per year, so as to more scientifically and objectively demonstrate the degree of global emission space occupied by countries.

In addition, the calculations and the results of this paper indicated that GHG emissions space use ratio was a scientific and impartial indicator for measuring the primary responsibility of various parties for GHG emissions and their obligation to control GHG emissions. Furthermore, this indicator does not directly show the GHG emission data information of each parties. Therefore, the openness and transparency of information about GHG emissions will not be impaired by the confidentiality of certain data and it can also support policy makers and all sectors of society to understand the degree of global emission space occupied by countries, and facilitate the equitable distribution of global emission allowance, to ensure that each country owns the equitable right to development while making the same proportion of contribution to global climate change, which was of high practical significance.

\section{Acknowledgements}

My work is support by National Key R\&D Program of China"Research on Trend Analysis and Comprehensive Evaluation of Non- $\mathrm{CO}_{2}$ Greenhouse Gas Emission in Planting and Breeding Industry" (Grant NO. 2017YFF021170 5). I thank Prof. Su Mingshan, my director, for providing necessary materials, professional guidance and inspiration on my thesis thinking, and Senior Engineer Yang Shanshan, Li Xiang for enlightening discussions and helpful comments on this manuscript.

\section{References}

[1] IPCC, Climate change 2014 Mitigation of Climate Change (R/OL), 2014.

[2] IPCC Fifth Assessment Report. Climate Change 2013: The Physical Science Ba sis (R). Stockholm, Sweden, 2013.

[3] EDF calculation based on IPCC AR5 WGI Chapter 8 (R/OL). $\mathrm{http}: / /$ www.ipcc.ch/report /ar5/ index.shtml.

[4] Su Mingshan. Ratio for Greenhouse Gas Emission per Capita per Year and Its Application to UNFCCC Parties (J). Climate Change Research, 2017, 13 (01): 69-75.

[5] China first mentioned the use of "accumulated carbon emissions per capita" in the "Poznan Negotiations" (J). Energy Conservation and Environmental Protection, 2009 (02): 10 .

[6] Miu Xuming. Research on Cumulative $\mathrm{CO}_{2}$ Emissions Per Capita and Obligations Based on Contribution Value (J). China Soft Science, 1998 (09): 18-23.

[7] Pan Jiahua, Zheng Yan. Responsibility and Individual Equity for Carbon Emissions Rights. (J). World Economics and Politics, 2009 (10): 6-16+3.

[8] He Jiankun, Liu Bin, Chen Wenying. Analysis on the Equity of Global Climate Change Issues (J). China Population, Resources and Environment, 2004 (06): 14-17.

[9] Liu Qiang, ChenYi, and Sun Fen. How big was China's future carbon dioxide emissions? (J). World Environment, 2014 (06): $22-25$.

[10] Wang Huihui, Liu Hengchen, He Xiaojia. Study of Carbon Emission Equity Based on the Perspective of Historical Cumulative Carbon Emission (J). China Population, Resources and Environment, 2016, 26 (S1): 22-25.

[11] Ding Zhongli, Duan Xiaonan, Ge Quansheng. Atmospheric $\mathrm{CO}_{2}$ concentration control in 2050: calculation of emission rights for various countries (J). Science in China (Series D: Earth Sciences), 2009, 39 (08): 1009-1027.

[12] UNFCCC. National report (R/OL), 2018. http://unfccc.int/ documents.

[13] IEA $\mathrm{CO}_{2}$ emission from fuel combustion: database ducumentation $\quad(\mathrm{R} / \mathrm{OL})$. 2019 http://wds.iea.org/wds/pdf/WorldCO ${ }_{2}$ Documentation. 
[14] Global Carbon Project (2019) (R/OL), 2019. https://www.icos-cp.eu/global-carbon-budget-2019.

[15] Boden, T., Marland, G., and Andres, R. J. Global Carbon Dioxide emissions from fossil fuel consumption and cement production, 2018. https://energy. appstate.edu/CDIAC.

[16] FAOSTAT. Emissions-Agriculture (R/OL), 2018. http://www.fao.org/faostat/en/\#data.
[17] Population Division of the Department of Economic and Social Affairs of the United Nations Secretariat. World population $\begin{array}{lll}\text { prospects } & 2019 & \text { (R/OL), }\end{array}$ https://population.un.org/wpp/Download/Standard/Population/. 